\title{
Isolated cranial nerve palsies in multiple sclerosis
}

Frank Thömke, Eckart Lensch, Kurt Ringel, Hanns Christian Hopf

\begin{abstract}
During a 10 year period 24 patients with definite multiple sclerosis with isolated cranial nerve palsies were studied (third and fourth nerve: one patient each, sixth nerve: 12 patients, seventh nerve: three patients, eighth nerve: seven patients), in whom cranial nerve palsies were the presenting sign in 14 and the only clinical sign of an exacerbation in 10 patients. MRI was carried out in 20 patients and substantiated corresponding brainstem lesions in seven patients (third nerve: one patient, sixth nerve: four patients, eighth nerve: two patients). Additional abnormal findings of electro-oculography, or masseter reflex, or blink reflex, or combinations of these were found in 20 patients and interpreted in favour of a brainstem lesion at the level of the respective cranial nerve. In 11 of 14 patients with isolated cranial nerve palsies as the presenting sign of multiple sclerosis, dissemination in space was documented by MRI, and in the remaining three by evoked potentials. In patients with multiple sclerosis with isolated cranial nerve palsies, MRI is the most sensitive method of documenting dissemination in space and electrophysi-
\end{abstract}

ological testing the most sensitive at disclosing brainstem lesions.

\section{(F Neurol Neurosurg Psychiatry 1997;63:682-685)}

Keywords: multiple sclerosis; cranial nerve palsy; magnetic resonance imaging; brainstem reflexes

Isolated cranial nerve palsies are rare clinical signs in multiple sclerosis. ${ }^{1-6}$ Previous studies lack information on the proportion of isolated cranial nerve palsies as the presenting sign of multiple sclerosis and on whether these palsies were really isolated or accompanied by additional signs of brainstem dysfunction. We provide more detailed information on isolated cranial neve palsies as the presenting sign of multiple sclerosis or the only clinical sign of an exacerbation, which is based on our own studies of 24 patients with isolated third, fourth, sixth, seventh, or eighth nerve palsies.

\section{Patients and methods}

During a 10 year period we studied 1218 patients with clinically definite multiple sclerosis (CDMS) and 271 with laboratory supported definite multiple sclerosis (LSDMS). Diagnosis of CDMS and LSDMS was based
Department of

Neurology

F Thömke

E Lensch

H C Hopf

Department of

Neuroradiology,

University of Mainz,

Germany

K Ringel

Correspondence to: Dr Frank Thömke,

Neurologische Uniklinik, Langenbeckstrasse 1, D-55101 Mainz, Germany. Telephone 004961317194 ; fax 004961313271

Received 10 February 1997 and in revised form 19 May 1997

Accepted 18 June 1997

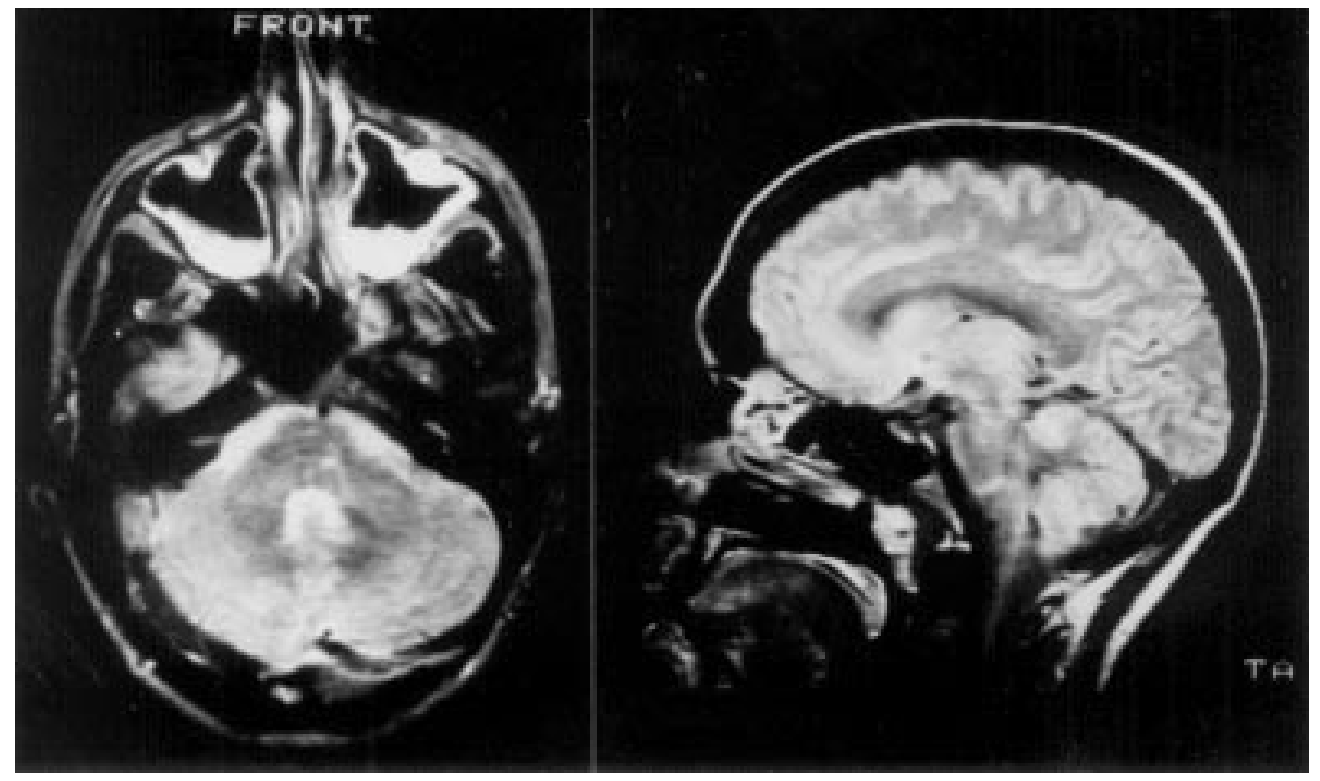

T2 weighted MRI of patient 6 with an isolated left sided sixth nerve palsy as the presenting sign of multiple sclerosis. Hyperintense lesions of the caudal pons involving the region of the ipsilateral intrapontine sixth nerve. 
on the criteria of Poser et $a l^{7}$ and Paty et $a l .{ }^{8}$ Isolated cranial nerve palsies were the presenting sign in 14 and the sole clinical sign of an exacerbation in 10 patients. DC electrooculography (EOG) including bithermal caloric testing, masseter reflex, blink reflex, brainstem auditory evoked potentials (BAEP), somatosensory evoked potentials (SEP), visual evoked potentials (VEP), and CSF has been examined routinely in these patients. MRI was carried out in 20 patients (13 with LSDMS, seven with CDMS). Re-examinations were carried out in 23 patients within two to eight weeks.

Methods of examining EOG, masseter reflex, blink reflex, BAEP, SEP, and VEP conformed to those previously described..$^{9-11}$ The MRI was performed on a Philips S scanner at a field strength of 1.5 Tesla (T2 weighted images, echo time: $80-100 \mathrm{~ms}$, repeat time: $1800-2080 \mathrm{~ms}$, slice thickness $3-5 \mathrm{~mm}$ for the pontomesencephalic brainstem, $7 \mathrm{~mm}$ for cerebral hemispheres).

\section{Results}

Isolated cranial nerve palsies were the presenting sign in 14 patients (third and fourth nerve: one patient each; sixth nerve: six patients; seventh nerve: three patients; eighth nerve: vestibular portion: three patients) (table). Five (patients 4, 5, 6, 10, and 14) had complete and the other nine incomplete palsies. Nine patients had pleocytosis (between 6 and 31 white cells $/ \mu \mathrm{l}$ ) and all oligoclonal banding. The table gives the abnormal electrophysiological findings. The MRI confirmed corresponding brainstem lesions in four of 13 examined patients (figure) (table), and documented dissemination in space in 11 patients. In the remaining three patients, disemination in space was documented by VEP (two patients), and SEP (one patient). Complete clinical recovery was seen in all patients within two to six weeks, which was associated with improvement of at least one electrophysiological abnormality (table).

In another 10 patients, isolated palsies of the sixth or eighth nerve were the only clinical sign of the second and third exacerbation (sixth nerve: six patients; eighth nerve, vestibular portion: three patients, cochlear portion one patient). Four (patients 16, 22, 23, and 24) had complete palsies and the other six they were incomplete. Oligoclonal banding was present in preceding lumbar punctures from all patients. The table gives the abnormal electrophysiological findings (all patients with unilaterally delayed VEPs had preceding optic neuritis, patients with SEP abnormalities had preceding myelitis or ipsilateral sensorimotor hemiparesis). MRI confirmed corresponding brainstem lesions in three of seven examined patients. Complete clinical recovery was seen in all patients within two to eight weeks, which was associated with recovery of at least one electrophysiological abnormality (table).

\section{Discussion}

Isolated cranial nerve palsies are rare clinical findings in multiple sclerosis ${ }^{1-6}$ and were seen in
24 of $1489(1.6 \%)$ consecutive patients in the present series. The palsies were the presenting sign in 14 of $271(5.2 \%)$ patients seen at the onset of multiple sclerosis and diagnosed as LSDMS on the basis of oligoclonal banding and dissemination in space. $^{78}$ Previously, cranial mononeuropathy was reported in 44 of $295(14.9 \%)$ patients at the onset of multiple sclerosis. ${ }^{1}$ This group, however, included an undetermined number of patients with additional signs of brainstem dysfunction and multiple cranial nerve palsies, thereby overestimating the frequency of cranial nerve palsies as the presenting sign in multiple sclerosis. We found isolated cranial nerve palsies significantly more often as the presenting sign in patients with LSDMS than the only clinical sign of an exacerbation in patients with CDMS (14 of 271 compared with 10 of 1218, $\chi^{2} 26.391$; $\mathrm{P}<0.001)$. It is well known that the number of patients with persistent clinical signs of involvement of the CNS increases with increasing number of exacerbations. Hence the probability of seeing patients with multiple sclerosis with cranial nerve palsies without additional neurological abnormalities decreases with increasing number of preceding exacerbations.

The sixth nerve was most often affected (in six of 14 patients with the first and in six of 10 patients with the second or third exacerbation). The sixth nerve runs through the pons as a compact bundle, whereas vestibular and third nerve fibres run intra-axially and are more spread out, which may contribute to the more frequent involvement of the sixth nerve. The probability of an intra-axial cranial nerve lesion in multiple sclerosis may also increase with increasing length of the intra-axial portion of the respective nerve, and the intrapontine sixth nerve is much longer than the intrapontine vestibular and the intramesencephalic third and fourth nerves. However, the intra-axial length cannnot be the chief determinant of cranial mononeuropathy in multiple sclerosis, as dysfunction of the seventh nerve, which has a longer intra-axial course than the sixth nerve, was less common in a previous study ${ }^{1}$ and this series. Possibly a partial sixth nerve lesion is more likely to be noted than a partial seventh nerve lesion; the first is followed by diplopia, whereas the second may escape detection as a mild facial palsy may be asymtomatic for the patient. Patients with trigeminal neuropathy as the only clinical sign of multiple sclerosis were missed in our series, although many patients report facial hypaesthesia during the early stages of multiple sclerosis. Such symptoms are troublesome but usually not disabling, so that the patients may not seek medical treatment as inpatients. (We found impaired trigeminal sensory functions only in inpatients with trigeminal neuralgias or additional clinical signs of brainstem dysfunction.)

MRI is the best method for showing dissemination in space, especially at the onset of multiple sclerosis, ${ }^{12}{ }^{13}$ and is also thought to be the most sensitive method to detect demyelinating brainstem lesions. ${ }^{14}{ }^{15}$ In accordance with this, MRI showed dissemination in space in 11 of 14 patients with isolated cranial 
nerve palsies as the presenting sign of multiple sclerosis, but confirmed corresponding brainstem lesions, which involved the region of the respective cranial nerve, in only seven (four with LSDMS, three with CDMS) of 20 patients examined. Ormerod et al, ${ }^{15}$ however, reported corresponding MRI abnormalites in 25 of 27 patients with clincially isolated brainstem lesions. This group included six patients with sixth and eight with seventh nerve dysfunction, but all of these patients had additional long tract and brainstem signs. ${ }^{15}$ Such lesions are expected to be bigger than lesions causing isolated cranial nerve palsies without additional signs of brainstem dysfunction, and bigger lesions are more likely to be detected by MRI than smaller ones, as shown by Rose et $a l^{4}{ }^{4}$ who confirmed pontine lesions in patients with multiple sclerosis with sixth nerve palsies and additional brainstem signs, but not in the only patient of their series with isolated sixth nerve palsy. Our findings indicate that some brainstem lesions may escape observation on MRI. Reports of patients with multiple sclerosis with isolated third or sixth nerve palsies without brainstem lesions established by $\mathrm{MRI}^{3{ }^{4}}$ or with internuclear ophthalmoplegia and impaired convergence as an indicator of midbrain lesions, which were confirmed by MRI in only four of nine patients, ${ }^{16}$ support this view. Moreover, MRI failed to confirm corresponding brainstem lesions in up to one third of patients with multiple sclerosis with BAEP and blink reflex abnormalities. ${ }^{17}$

Additional electrophysiological abnormalities were seen in 22 of our 24 patients (table) and were attributed to structures near the midline adjacent to the respective cranial nerves. These structures include the central masseter reflex arc in patients with MR abnormalities, the medial longitudinal fasciculus in patients with slowed adduction, or the intrapontine

Table 1 Abnormal electrophysiological findings and MRI established brainstem lesions in 24 patients with multiple sclerosis and isolated cranial nerve palsies as the presenting sign or the sole clinical manifestation of an exacerbation

\begin{tabular}{|c|c|c|c|c|c|c|c|c|c|}
\hline \multirow{2}{*}{$\frac{\text { Bout }}{1 \mathrm{st}}$} & \multirow{2}{*}{ No } & \multirow{2}{*}{$\frac{\text { Age }}{50}$} & \multirow{2}{*}{$\begin{array}{l}\text { Sex } \\
\mathrm{F}\end{array}$} & \multirow{2}{*}{$\frac{\text { Nerve }}{3 \text { rd }}$} & \multicolumn{5}{|c|}{ Abnormal electrophysiological and MRI findings } \\
\hline & & & & & EOG & \multicolumn{4}{|c|}{ Contralaterally slowed adduction saccades (n) } \\
\hline & & & & & MR & Ipsilateral & 7.9 & 8.7 & $9.6 \mathrm{~ms}$ \\
\hline & & & & & & Contralateral & 9.0 & 9.3 & $9.5 \mathrm{~ms}$ \\
\hline & & & & & MRI & \multicolumn{4}{|c|}{ Periaqueductal midbrain lesion } \\
\hline \multirow{2}{*}{$1 \mathrm{st}$} & 2 & 30 & M & 4th & MR & Ipsilateral & 7.2 & 7.61 & \\
\hline & & & & & & Contralateral & 7.7 & 7.91 & \\
\hline $1 \mathrm{st}$ & 3 & 30 & $\mathrm{~F}$ & 6th & EOG & \multicolumn{4}{|c|}{ Ipsilateral vestibular paresis (n) } \\
\hline $1 \mathrm{st}$ & 4 & 29 & $\mathrm{M}$ & 6th & EOG & \multicolumn{4}{|c|}{ Contraversive directional preponderance (n) } \\
\hline \multirow[t]{3}{*}{$1 \mathrm{st}$} & 5 & 36 & $M$ & 6th & EOG & \\
\hline & & & & & & \multicolumn{4}{|c|}{$\begin{array}{l}\text { Optokinetic nystagmus: reduced gain of contraversive following eye } \\
\text { movements }(n)\end{array}$} \\
\hline & & & & & MRI & \multicolumn{4}{|c|}{ Ipsilateral pontine lesion } \\
\hline \multirow[t]{3}{*}{$1 \mathrm{st}$} & 6 & 33 & $\mathrm{~F}$ & 6th & EOG & \multirow{2}{*}{\multicolumn{4}{|c|}{$\begin{array}{l}\text { Contralaterally slowed abduction an adduction saccades }(n) \\
\text { Optokinetic nystagmus: reduced gain of contraversive following eye } \\
\text { movements }(n)\end{array}$}} \\
\hline & & & & & & & & & \\
\hline & & & & & MRI & \multicolumn{4}{|c|}{ Ipsilateral pontine lesion } \\
\hline $1 \mathrm{st}$ & 7 & 19 & $\mathrm{~F}$ & 6th & EOG & Contralatera & oducti & accad & \\
\hline & & & & & & Hypometric & e sacc & (i) & \\
\hline & & & & & SEP & Unilaterally de & & & \\
\hline $1 \mathrm{st}$ & 8 & 25 & $\mathrm{~F}$ & 6th & EOG & Contraversive & repon & ince ( & \\
\hline & & & & & MRI & Ipsilateral pon & & & \\
\hline $1 \mathrm{st}$ & 9 & 23 & M & 7th & EOG & Saccadic pursu & ments & & \\
\hline $1 \mathrm{st}$ & 10 & 24 & $\mathrm{~F}$ & 7th & VEP & Unilateral dela & & & \\
\hline $1 \mathrm{st}$ & 11 & 30 & $M$ & 7th & VEP & Unilateral dela & & & \\
\hline $1 \mathrm{st}$ & 12 & 24 & $\mathrm{~F}$ & 8 th vest & EOG & Ipsilaterally slo & ion sac & es (n) & \\
\hline $1 \mathrm{st}$ & 13 & 25 & $\mathrm{~F}$ & 8 th vest & EOG & $\begin{array}{l}\text { Optokinetic ny } \\
\text { movements (n) }\end{array}$ & luced & of ip & rsive following eye \\
\hline & & & & & MR & Ipsilateral & 7.8 & 5.31 & \\
\hline & & & & & & Contralateral & 7.1 & $5.4 \mathrm{r}$ & \\
\hline $1 \mathrm{st}$ & 14 & 43 & $\mathrm{~F}$ & 8 th vest & MR & Ipsilateral & 7.2 & 5.91 & \\
\hline & & & & & & Contralateral & 7.7 & $7.0 \mathrm{r}$ & \\
\hline 2nd & 15 & 24 & $\mathrm{~F}$ & 6th & EOG & Contralaterally & uction & cades & \\
\hline 2 nd & 16 & 28 & $\mathrm{~F}$ & 6th & EOG & Contralaterally & uction & cades & \\
\hline & & & & & MR & Ipsilateral & 7.6 & $7.5 \mathrm{r}$ & \\
\hline & & & & & & Contralateral & 8.2 & 9.01 & \\
\hline & & & & & MRI & Ipsilateral pon & & & \\
\hline 2nd & 17 & 30 & $\mathrm{~F}$ & 6 th & $\mathrm{EOG}$ & Contraversiv & prepc & erance & \\
\hline & & & & & & Ipsiversive s & uit eye & veme & \\
\hline 2nd & 18 & 33 & $\mathrm{~F}$ & 6th & EOG & Contralaterally & uction & cades & \\
\hline & & & & & & Saccadic pursu & ments & & \\
\hline & & & & & MR & Ipsilateral & 7.4 & $7.9 \mathrm{r}$ & \\
\hline & & & & & & Contralateral & 6.6 & 7.11 & \\
\hline 2 nd & 19 & 28 & $\mathrm{~F}$ & 8 th vest & MR & Ipsilateral & $7.4 \mathrm{n}$ & & \\
\hline & & & & & & Contralateral & $6.5 \mathrm{n}$ & & \\
\hline 2 nd & 20 & 30 & M & 8 th vest & MRI & Ipsilateral pon & & & \\
\hline $3 \mathrm{rd}$ & 21 & 32 & $\mathrm{~F}$ & 6 th & EOG & Ipsiversive sacc & eye $\mathrm{m}$ & ment & \\
\hline & & & & & & Abnormal fi & ession & psiver & nystagmus (n) \\
\hline $3 \mathrm{rd}$ & 22 & 36 & $\mathrm{~F}$ & 6th & EOG & Saccadic pu & vemen & & \\
\hline & & & & & & Slowed cont & cades & & \\
\hline & & & & & BR-R1 & Ipsilateral & 11.5 & 11.6 & \\
\hline & & & & & & Contralateral & 13.5 & 12.1 & \\
\hline $3 \mathrm{rd}$ & 23 & 32 & $\mathrm{~F}$ & 8th coch & EOG & Ipsilaterally & ction s & ades & \\
\hline & & & & & & $\begin{array}{l}\text { Optokinetic } \\
\text { directions (i) }\end{array}$ & reduce & in of & owing eye movements in both \\
\hline $3 \mathrm{rd}$ & 24 & 37 & $\mathrm{~F}$ & 8 th vest & MRI & Ipsilateral pon & & & \\
\hline
\end{tabular}

8 th vest $=$ vestibular portion of the 8 th nerve; 8 th $\operatorname{coch}=$ cochlear portion of the 8 th nerve; EOG $=$ electro-oculography; $\mathrm{MR}=$ masseter reflex; BR-R1 = R1 component of the blink reflex; VEP = visual evoked potentials; SEP = somatosensory evoked potentials; $(\mathrm{n})=$ normalisation; $(\mathrm{i})=$ improvement. 
sixth nerve in patients with slowed abduction saccades. Recovery of cranial nerve palsies was almost always associated with improvement of electrophysiological abnormalities, strongly indicating that both were caused by a single asymmetric lesion in the midline. Abnormalities in BAEP were not seen in our patients, which may be due to the anatomical organisation of central auditory pathways. These connections are located in lateral brainstem regions, whereas the third, fourth, sixth, and seventh nerves run near the midline.

In conclusion, isolated cranial nerve palsies are rare clinical findings in multiple sclerosis, occurring, in our experience, in $1.6 \%$ of all patients and in $5.2 \%$ as the presenting sign. In these, as in other patients with multiple sclerosis, MRI is the most sensitive method of documenting dissemination in space, but MRI may fail to confirm corresponding brainstem lesions in many patients with isolated cranial nerve palsies. In these patients, electrophysiological tests seem to be more sensitive in disclosing brainstem dysfunction at the level of the affected cranial nerve.

We are grateful to Dr L Gutmann, Department of Neurology, West Virginia University, Morgantown WV, USA, for his helpful comments on the manuscript.

1 Kahana E, Leibowitz U, Alter M. Brainstem and cranial nerve involvement in multiple sclerosis. Acta Neurol Scand 1973;49:269-79.

2 Matthews WB. Symptoms and signs. In: Matthews WB, Acheson ED, Batchelor JR, Weller RO, eds. McAlpine's multiple sclerosis, 3rd ed. Edinburgh: Churchill Livingstone, 1985:96-145.

3 Newman NJ, Lessell S. Isolated pupil-sparing third-nerve palsy as the presenting sign of multiple sclerosis. Arch Neurol 1990;47:817-8.
4 Rose JW, Digre KB, Lynch SG, Harnsberger RH. Acute VIth cranial nerve dysfunction in multiple sclerosis. fournal of Clinical Neuroophthalmology 1992;12:17-20.

5 Sturzenegger $M$. Isolated sixth-nerve palsy as the presenting sign of multiple sclerosis. Neuroophthalmology 1994;14:438.

6 Drulovic B, Ribaric-Jankes K, Kostic VS, Sternic N. Sudden hearing loss as the initial monosymptom of multiple sclerosis. Neurology 1993;43:2703-5.

7 Poser C, Paty D, Scheinberg L, McDonald WI, Davis F, et al. New diagnostic criteria for multiple sclerosis: guidelines for research protocols. Ann Neurol 1983;13:227-31.

8 Paty DW, Asbury AK, Herndon RM, McFarland HF, McDonald WI, et al. Use of magnetic resonance imaging in the diagnosis of multiple sclerosis: policy statement. Neurolgy 1986;36:1575.

9 Thömke F, Hopf HC, Krämer G. Internuclear ophthalmoplegia of abduction: clinical and electrophysiological data on the existence of an abduction paresis of prenuclear origin. F Neurol Neurosurg Psychiatry 1992;55:105-11.

10 Chiappa KH. Pattern-shift visual evoked potentials: methodology. In: Chiappa KH, ed. Evoked potentials in clinical medicine. New York: Raven Press, 1990:37-109.

11 Chiappa KH. Brainstem auditory evoked potentials: methodology. In: Chiappa $\mathrm{KH}$, ed. Evoked potentials in methodology. In: Chiappa KH, ed. Evoked potentials in
clinical medicine. New York: Raven Press, 1990:174-221.

12 Ormerod IEC, Miller DH, McDonald WI, du Boulay EPGH, Rudge $\mathrm{P}$, et al. The role of MRI imaging in the assessment of multiple sclerosis and isolated neurological lesions. Brain 1987;110:1579-616.

13 Paty DW, Oger JJF, Kastrukoff LF, Hashimoto SA, Hooge $\mathrm{JP}$, et al. MRI in the diagnosis of MS: a prospective study with comparision of clinical evaluation, evoked potentials, oligoclonal banding, and CT. Neurology 1988;38:180-5.

14 Bogousslavsky J, Fox AJ, Carey LS, Vinitski S, Bass B, et al. Correlates of brain-stem oculomotor disorders in multiple sclerosis. Magnetic resonance imaging. Arch Neurol 1986; 43:460-3.

15 Ormerod IEC, Bronstein A, Rudge P, Johnson G, Macmanus $\mathrm{D}$, et al. Magnetic resonance imaging in clinically isolated lesions of the brain stem. F Neurol Neurosurg Psychiatry 1986;49:737-43

16 Bronstein AM, Rudge P, Gresty MA, du Boulay G, et al. Abnormalities of horizontal gaze. Clinical, oculographic and magnetic resonance imaging findings. II. Gaze palsy and internuclear ophthalmoplegia. F Neurol Neurosurg Psychiatry 1990;53:200-7.

17 Uncini A, Faricelli, Assetta M, Serio A, Tartaro A, et al. Electrophysiological and magnetic resonance imaging correlates of brainstem demyelinating lesions. Electromyogr Clin Neurophysiol 1990;30:233-8. 